\title{
Schooling impacts on the overactive bladder diagnosis in women
}

\author{
Larissa R. Ferreira ${ }^{1}$, Monica 0. Gameiro 2, Paulo R. Kawano ${ }^{3}$, Hamilto A. Yamamoto ${ }^{1}$, Rodrigo Guerra ${ }^{3}$, \\ Leonardo 0. Reis ${ }^{3}$, João L. Amaro ${ }^{1}$ \\ ${ }^{1}$ Departamento de Urologia, Faculdade de Medicina de Botucatu, Universidade Estadual Paulista, \\ Botucatu, Brasil; ${ }^{2}$ Serviço de Reabilitação Perineal, Faculdade de Medicina de Botucatu, Universidade \\ Estadual de São Paulo, Botucatu, Brasil; ${ }^{3}$ Faculdade de Medicina de Campinas, Pontifícia Universidade \\ Católica de Campinas - PUC Campinas, Campinas, Brasil
}

\section{ABSTRACT}

Objective: To evaluate the overactive bladder (OAB) diagnosis using OAB-V8 and ICIQ$\mathrm{OAB}$ questionnaires in women with different schooling and cultural levels.

Materials and Methods: Three hundred and eighty six healthy women answered a clinical questionnaire filling out information about schooling, demographic and gynecological data. The OAB-V8 and ICIQ-OAB questionnaires were used to evaluate OAB diagnosis and symptoms; and the QS-F questionnaire, to determine the sexual function. All questionnaires were validated in Portuguese.

Results: The mean age was 37.3 years-old. Regarding to schooling level, 23.1\% had concluded primary education; 65.8\%, secondary school; and 11.1\% had higher education. Considering the OAB-V8 (score $\geq 8$ ), 51.8\% of evaluated women had OAB diagnosis. There was a positive linear correlation between the OAB-V8 and ICIQ-OAB questionnaires in its sections " $a$ " $(r=0.812, p<0.001)$ and " $b$ " $(r=759, p<0.001)$. There was a positive linear correlation between age and the amount of time used to answer the OAB-V8, ICIQ-OAB and QS-F questionnaires $(\mathrm{p}<0.001)$.

The ICIQ-OAB was the hardest to answer for all schooling levels when compared to the other questionnaires. Women who had concluded primary and secondary education significantly demanded more help to answer all questionnaires than those with higher education $(\mathrm{p}<0.05)$. Furthermore, women with higher education took significantly less time answering all questionnaires when compared to their less educated counterparts (primary and secondary schooling), since they were quicker to answer each individual question.

Conclusion: Educational level and ageing had an impact on women response using different questionnaires for $\mathrm{OAB}$ and sexual function evaluations.

\section{ARTICLE INFO}

\section{Keywords:}

Women; Urinary Bladder;

Diagnosis

Int Braz J Urol. 2017; 43: 1129-35

Submitted for publication:

October 18, 2016

Accepted after revision:

April 22, 2017

Published as Ahead of Print: June 29, 2017

\section{INTRODUCTION}

Overactive Bladder $(\mathrm{OAB})$ is defined by the International Continence Society (ICS) as urinary urgency usually accompanied by an increase in urinary frequency and nocturia, with or without urinary incontinence, in the absence of other local diseases (1).
The prevalence of this condition is high, as well as its impact on quality of life. It is estimated that in 2018, approximately 546 million people will suffer of this problem (2). In southern Brazil, it is estimated that approximately $18 \%$ of the population present symptoms of overactive bladder (3).

The use of specific clinical questionnaires can be an important tool in the $\mathrm{OAB}$ evalua- 
tion and diagnosis. These questionnaires assess the symptoms severity, the discomfort degree, and the influence on quality of life (4). Additionally, different authors have proposed the use of specific questionnaires for the evaluation of sexual function in $\mathrm{OAB}$ patients (5).

The OAB-V8 is a simplified version adapted from the symptom Bother Scale of the overactive bladder questionnaires (OAB-q), validated to Portuguese that may be used in $\mathrm{OAB}$ diagnosis. It consists of eight questions with domains of 0 to 5 and $\mathrm{OAB}$ is considered a probable diagnosis when the score is equal to or higher than eight $(6,7)$.

Due to a lack of studies evaluating the agreement and accuracy between the questionnaires used in the $\mathrm{OAB}$ diagnosis, this study proposed to estimate the impact of $\mathrm{OAB}$ on sexual function, and the agreement between the OAB-V8 and ICIQ-OAB questionnaires in women, considering different social and economic status.

\section{MATERIALS AND METHODS}

Three hundred eighty-six healthy women, aged 18 years or older, were included from three different centers: 129 participants from the Physiotherapy Service; 129 from the Rehabilitation Center and 128 from the Hospital Estadual. As the study was developed in three different rehabilitation centers, we estimated the proportion of responders for each of them, taking into account the amount of care in each service.

All interviewed participants were undergoing physiotherapeutic treatment for non-urological complains, most of them, as companions of patients who were followed in these centers. Women were simply approached in the waiting room of these physiotherapy centers while waiting for care.

All participants were informed about the research, and, if they agreed to participate, they signed the free informed consent approved by the Ethical Research Board. The women answered a clinical questionnaire, which filled out information about schooling, demographic and gynecological data. The $\mathrm{OAB}-\mathrm{V} 8$ and ICIQ-OAB questionnaires were used to evaluate $\mathrm{OAB}$ diagnosis and symptoms; the QS-F questionnaire was used to evaluate sexual function. All questionnaires were validated in Portuguese.
The OAB-V8 questionnaire consists of eight questions, with domains range between 0 to 5 , and if the result is equal to or greater than 8 there is a probable diagnosis of overactive bladder (6).

The ICIQ-OAB evaluates the OAB symptoms in the "a" questions, and quality of life in the " $b$ " questions, and highest scores correspond to worse situation regarding to a particular disorder (8).

The QS-F consists of 10 questions that evaluate all stages related to sexual function in women; the higher the score was, more favorable the situation (9).

The participants were subsequently invited to answer three questions: 1 - Which questionnaire did you find the hardest to answer?; 2- Did you need to ask for help answering them?; 3- Which questionnaire demanded the most time for you to answer, in terms of minutes? The response time of each questionnaire was always recorded by the same researcher (a physiotherapist) using a digital chronometer.

The categorization of the schooling level of participants was established according to the organization and structure of education established by the Brazilian Ministry of Education (MEC) considering the information provided by the respondents (10).

\section{Statistical analysis}

The sample size was determined using casual participation of the subject to the survey, considering the probability of 50\% that each person would accept or not to participate in the study, estimating 10\% standard error and 5\% significance level for the conclusions.

Considering that the study was developed in three different rehabilitation centers, we estimated a proportion of responders for each of them, taking into account the amount of care in each service. The total sample size was calculated as 384 (11).

For clinical and demographic data analysis, the nonparametric chi-square test was used (12). The measurement of the strength of the linear relationship between the different variables was performed by the Pearson Correlation Coefficient 
when the variables were quantitative, and the Godman's Test was applied to establish the contrasts between qualitative variables within multinomial populations.

The Bonferroni Method was used to evaluate the variance analysis for models of repeated measures in independent groups (13-15).

\section{RESULTS}

Clinical and demographic data of the study population are summarized in Table-1. Associated comorbidities were observed in $25 \%$ of participants: hypertension (10.6\%), hypothyroidism (3.6\%), Diabetes mellitus (2.1\%), and other diseases $(8.7 \%)$.

In 51.8\%, the symptoms score was higher than or equal to 8 using $\mathrm{OAB}-\mathrm{V} 8$, representing probable OAB diagnosis (6).

Average scores questions on the sections "a" and " $b$ " of the ICIQ-OAB questionnaire was $3.08 \pm 0.16$, and $7.19 \pm 0.61$, respectively.

There was a positive linear correlation between the OAB-V8 and OAB ICIQ-scores in both sections "a" ( $\mathrm{r}=0.812, \mathrm{p}<0.001)$, and "b" $(\mathrm{r}=0.759$, $\mathrm{p}<0.001$ ).

Average QS-F score was $61.48 \pm 1.5$, demonstrating that sexual performance in the women varied from regular to good (9).

There was a positive linear correlation between age and response time in all questionnaires, suggesting that older women need longer time to answer these questionnaires (Table-2).

There was a negative linear correlation between the OAB-V8 questionnaire as compared to the QS-F ( $\mathrm{r}=-0.519, \mathrm{p}=0.033)$.

ICIQ-OAB questionnaire was significantly more difficult to answer when compared to other ones in all level of education. However, there was no statistical difference among the different levels of education considering each questionnaire separately (Table-3).

Women with higher educational levels needed less assistance to answer any of the questionnaires when compared to other educational levels. However, in higher level about 15\% of participants required some degree of help during filling out of OAB-V8 (Table-4).

Table 1 - Clinical and demographic data of the study population.

\begin{tabular}{|c|c|c|c|c|}
\hline \multicolumn{5}{|c|}{ Characteristics of the population studied } \\
\hline Variable & Mean & Variable & Total & $\%$ \\
\hline Age & $37.3(14.4)$ & Skin color* & & \\
\hline BMI & $27.0(5.6)$ & White & 288 & 74.6 \\
\hline Pregnancies & $1.6(1.8)$ & Mulatto & 69 & 17.9 \\
\hline Vaginal delivery & $0.6(1.3)$ & Yellow & 9 & 2.2 \\
\hline C-sections & $0.8(1.1)$ & Black & 20 & 5.2 \\
\hline \multicolumn{5}{|c|}{ Civil status* } \\
\hline & & Married & 196 & 50.8 \\
\hline & & $\begin{array}{l}\text { Separated/ } \\
\text { divorced }\end{array}$ & 24 & 6.2 \\
\hline & & Widow & 14 & 3.6 \\
\hline & & Single & 152 & 39.4 \\
\hline \multicolumn{5}{|c|}{ Education* } \\
\hline & & Primary & 89 & 23.1 \\
\hline & & Secondary & 254 & 65.8 \\
\hline & & Higher & 43 & 11.1 \\
\hline
\end{tabular}

* Categorical variables of the population studied, divided into sample size and their respective percentage 
Table 2 - Pearson linear correlation: age versus time to answer the questionnaires.

\begin{tabular}{lcc}
\hline & \multicolumn{2}{c}{ Linear correlation } \\
\hline Association & "r" Value & "p" Value \\
\hline Age $\times$ Time OAB-V8 & 0.190 & $p<0.001$ \\
Age $\times$ Time ICIQ-OAB & 0.281 & $p<0.001$ \\
Age $\times$ Time QS-F & 0.291 & $p<0.001$ \\
\hline
\end{tabular}

Table 3 - Number and percentage of women considering ease to answer the different questionnaires according to educational levels.

\begin{tabular}{lcccc}
\hline Education & OAB-V8 & ICIQ-OAB & QS-F & Total \\
\hline Primary & $20(42.6 \%)$ aB & $6(12.8 \%)$ aA & $21(44.6 \%)$ aB & $47(100 \%)$ \\
Secondary & $66(41.0 \%)$ aB & $38(9.8 \%)$ aA & $57(35.4 \%)$ aB & $161(100 \%)$ \\
Higher & $10(55.6 \%)$ aB & $2(11.1 \%)$ aA & $6(33.3 \%)$ aAB & $18(100 \%)$ \\
\hline Total & $96(100 \%)$ & $46(100 \%)$ & $84(100 \%)$ & $226(100 \%)$ \\
\hline
\end{tabular}

Different lower cases mean statistically significant differences among educational level in the same questionnaire.

Different upper cases mean statistically significant difference considering different questionnaires in the same educational level.

Table 4 - Number and percentage of women who needed assistance to answer the questionnaires according to the level of education.

\begin{tabular}{lcccc}
\hline Education & OAB-V8 & ICIQ-OAB & QS-F & Total \\
\hline Primary & $5(38.4 \%) \mathbf{b A}$ & $4(30.8 \%) \mathbf{b A}$ & $4(30.8 \%) \mathbf{b A}$ & $13(100 \%)$ \\
Secondary & $33(46.4 \%) \mathbf{b A}$ & $19(26.8 \%) \mathbf{b A}$ & $19(26.8 \%) \mathbf{b A}$ & $71(100 \%)$ \\
Higher & $3(15.2 \%) \mathbf{a B}$ & $0(0 \%) \mathbf{a A}$ & $0(0 \%) \mathbf{a A}$ & $3(100 \%)$ \\
\hline Total & $41(100 \%)$ & $23(100 \%)$ & $23(100 \%)$ & $87(100 \%)$ \\
\hline
\end{tabular}

Different lower cases mean statistically significant differences among educational level in the same questionnaire.

Different upper cases mean statistically significant difference considering different questionnaires in the same educational level.

It was found a significantly shorter time to answer the questions in all questionnaires in higher education level when compared to other educational levels (Table-5). Similar results were observed when compared secondary and primary education levels (Table-5), demonstrating the importance of this parameter in the evaluation of patients using specific questionnaires.

\section{DISCUSSION}

According to AUA guidelines, $\mathrm{OAB}$ is not a disease; it is a symptom complex that generally is not a life-threatening condition. In this context, in pursuing a treatment plan the clinician should carefully weigh the potential benefit to the patient of a particular treatment against that treatment's risk for adverse events and its severity and reversibility. However, if after the assessment has been performed to exclude conditions requiring treatment and counseling, no treatment is an acceptable choice made by some patients and caregivers (16).

Once $O A B$ is determined by subjective and objective symptoms, the patient's perspective is very important in the proper management of this important condition. The diagnosis of this clinical syndrome is based on detailed history, physical examination, and urine analysis. Additionally, $\mathrm{OAB}$ may negatively affect sexual activity and or- 
Table 5 - Response time (seconds) for each questionnaire according to education level.

\begin{tabular}{lccc}
\hline Education & OAB-V8 & ICIQ-OAB & QS-F \\
\hline Primary & $134.4 \pm 56.5 \mathbf{c}$ & $137.1 \pm 55.7 \mathbf{c}$ & $200.1 \pm 79.6 \mathbf{c}$ \\
Secondary & $107.6 \pm 40.0 \mathbf{b}$ & $107.2 \pm 35.8 \mathbf{b}$ & $146.6 \pm 46.3 \mathbf{b}$ \\
Higher & $89.7 \pm 34.7 \mathbf{a}$ & $91 \pm 28.5 \mathbf{a}$ & $123 \pm 40.6 \mathbf{a}$ \\
$\mathbf{p}$ Value & $\mathrm{p}<0.001$ & $\mathrm{p}<0.001$ & $\mathrm{p}<0.001$ \\
\hline
\end{tabular}

Different lower cases mean statistically significant differences different educational levels.

gasm. Different authors have demonstrated decrease in the orgasm in these patients (5).

For this reason, several diagnostic tools evaluating patient reported outcomes are proposed in attempt to help diagnosis. In some patients, the voiding diary may be used, as well as the measures of post-void residual urine (4). More complex diagnostic procedures such as urodynamic study may be not necessary, and it is reserved only to specific cases such as in neurologic disease, high post-void residue or pharmacological treatment failure (17).

The ICIQ-OAB questionnaire has level "A" of evidence, and provides assessment of urinary symptoms such as frequency and urgency, and also measures their impact on quality of life. Bothersome related to $\mathrm{OAB}$ symptoms are worse when final questionnaires score is higher (8).

Some authors have reported that age, BMI, pregnancy, type of delivery, and ethnicity may influence the incidence of $\mathrm{OAB}$ diagnosed by validated questionnaires (18-20). Considering the World Health Organization (WHO) (21) classification, we noted that most of women in our study were white overweight mature adults.

In our population, the most common comorbidities were arterial hypertension and Diabetes mellitus (DM). Some authors had stated that these comorbidities and depression might be associated with $\mathrm{OAB}(22,23)$.

We observed a probable $\mathrm{OAB}$ diagnosis in more than half of women using the OAB-V8 questionnaire. Davila et al. (24) reported similar results (51\%) using the same questionnaire, and also questioned the reliability of isolated use of this instrument for $\mathrm{OAB}$ diagnosis. Thus, if we consider only the OAB-V8 questionnaire our outcomes may be overestimated.

Lapitan et al. (25) identified a global prevalence of $\mathrm{OAB}$ of $53.1 \%$ in an Asian female population, using a questionnaire specific to the region. Other studies report a prevalence ranging from $11.8 \%$ to $18.9 \%$ using different questionnaires $(2,26,27)$. Some authors attribute this variation in prevalence rates to the different definitions and questionnaires used for the diagnosis of $\mathrm{OAB}$ (28). Scafuri et al. (29) stated that it is difficulty to select the adequate tools for assessment and diagnosis of $\mathrm{OAB}$, impacting the divergences of $\mathrm{OAB}$ prevalence among different studies.

In Brazil, the questionnaires frequently used for $O A B$ prevalence are not specific. So, using a specific questionnaire, we found a high prevalence of this disorder. It's important to remember that in our protocol we evaluated only female participants.

In their study, Teloken et al. concluded that overactive bladder is a highly prevalent condition, even in young populations (3). It affects both genders, yet it is more frequently observed in women $(14.0 \%$ in men versus $23.2 \%$ in women; overall 18.9\%). According to the author, the lack of standardization in the diagnosis and utilization of different criteria in scientific papers may hinder a comparative analysis.

Additionally, they applied a different strategy to evaluate their patients, once they use a questionnaire developed by the combination of questions from the King's Health Questionnaire validated for $\mathrm{OAB}$ syndrome, the AUA Symptoms Score and original questions.

Although our study has shown a possible overestimation in the $\mathrm{OAB}$ prevalence, there was a positive linear correlation between the $\mathrm{OAB}-\mathrm{V} 8$ 
and ICIQ-OAB questionnaires, demonstrating that there was concordance in the $\mathrm{OAB}$ diagnosis and the answers about worsening on $\mathrm{OAB}$ symptoms and quality of life.

In the present study, the longer response time in all questionnaires observed in elderly women may reflect a reduced cognitive capacity resulting from the physiological aging process and mild cognitive decline, characterized by memory and attention deficits (30).

According to Vallet (31), some alterations in perception and cognition may occur during the process of physiological aging, such as reduced cognitive processing ability, reduced attention in the execution of some functions, as well as reduction in the ability of free recall and in episodic memory.

We observed that women had more difficulty in answering the ICIQ-OAB questionnaire in comparison to $\mathrm{OAB}-\mathrm{V} 8$. This fact is in disagreement with other authors that have described the ICIQ-OAB as a single and objective questionnaire to assess the storage symptoms related to $\mathrm{OAB}(32$, 33), suitable to use in different groups, young or elderly patients.

The QS-F questionnaire was specifically developed for the Brazilian population to evaluate the female sexual function. Actually, the studies available so far do not discuss or compare the response time with the level of education $(9,34)$. We observed a clear influence of the education level and the response time, demonstrating that women with higher level of education needed short time to answer these questionnaires. To our knowledge this is the first report in the current literature to address this question.

Our results showed that women who had only primary and secondary levels of education needed more assistance to answer the questionnaires. Some authors have reported that individuals with higher levels of education could solve more easily some problems and specific cognitive functions $(35,36)$. These facts justify why women with higher levels of education had shorter response time and less assistance to answer the questions in our study.

There was a negative linear correlation between the specific questionnaire for $\mathrm{OAB}$ symptoms and sexual function (SF), where higher scores for
OAB-related symptoms had worst results in SF. This fact demonstrates the negative influence of $\mathrm{OAB}$ symptoms in sexual performance.

In conclusion, educational level and ageing had an impact on women response using different questionnaires for $\mathrm{OAB}$ and SF evaluations.

\section{Ethics Committee}

Approval Ethics Committee: 1013798/2015. Ethics Committee: Faculty of Medicine of Botucatu - UNESP, SP, Brasil

\section{CONFLICT OF INTEREST}

None declared.

\section{REFERENCES}

1. Abrams P, Cardozo L, Fall M, Griffiths D, Rosier P, Ulmsten $U$, et al. Standardisation Sub-committee of the International Continence Society. The standardisation of terminology of lower urinary tract function: report from the Standardisation Sub-committee of the International Continence Society. Neurourol Urodyn. 2002;21:167-78.

2. Irwin DE, Kopp ZS, Agatep B, Milsom I, Abrams P. Worldwide prevalence estimates of lower urinary tract symptoms, overactive bladder, urinary incontinence and bladder outlet obstruction. BJU Int. 2011;108:1132-8.

3. Teloken C, Caraver F, Weber FA, Teloken PE, Moraes JF, Sogari $P R$, et al. Overactive bladder: prevalence and implications in Brazil. Eur Urol. 2006;49:1087-92.

4. Verdejo-Bravo C, Brenes-Bermúdez F, Valverde-Moyar MV, Alcántara-Montero A, Pérez-León N. Consensus document on overactive bladder in older patients. Ver Esp Geriatr Gerontol. 2015;50:247-56.

5. Proietti S, Giannantoni A, Sahai A, Khan MS, Dasgupta P. Overactive bladder and sexual function: a nightmare couple. BJU Int. 2012;110:921-4.

6. Coyne KS, Zyczynski T, Margolis MK, Elinoff V, Roberts RG Validation of na overactive bladder awareness tool for use in primary care settings. Adv Ther. 2005;22:381-94.

7. Acquadro C, Kopp Z, Coyne KS, Corcos J, Tubaro A, Choo MS, et al. Translating overactive bladder questionnaires in 14 languages. Urology. 2006;67:536-40. Erratum in: Urology. 2007;69:202. Oh, Seung June [added].

8. Pereira SB, Thiel Rdo R, Riccetto C, Silva JM, Pereira LC, Herrmann V, et al. Validation of the International Consultation on Incontinence Questionnaire Overactive Bladder (ICIQ-OAB) for Portuguese. Rev Bras Ginecol Obstet. 2010;32:273-8. 
9. Abdo CHN: Quociente sexual feminino: um questionário brasileiro para avaliar a atividade sexual da mulher. Diagn Tratamento. 2009; 14:89-91.

10. Governo Federal do Brasil [internet]. Saiba como é a divisão do sistema de educação brasileiro [update 2014 July 30; cited 2017 May 05]. Portal Brasil [about 2p]. Available from: $<$ <ttp://www.brasil.gov.br/educacao/2014/05/saiba-como-ea-divisao-do-sistema-de-educacao-brasileiro/view>

11. Cochran WG: Técnicas de amostragem. Rio de Janeiro: Fundo de Cultura, 1965.

12. Zar JH: Biostatistical analysis, 5ed. New Jersey: ReuticeHall, 2009; pp. 994

13. Goodman LA: Simultaneous confidence intervals for contrasts among multinomial populations. Annals of mathematical statistics. 1964; 32:716-25.

14. Goodman LA: Simultaneous confidence intervals for multinomial proportions. Technometrics. 1965; 7: 247- 54.

15. Johnson RA, Wichern DW. Applied multivariate statistical analysis. 6. Ed. New Jersey: Prentice - Hall, 2017; pp. 800.

16. Gormley EA, Lightner DJ, Faraday M, Vasavada SP; American Urological Association; Society of Urodynamics, Female Pelvic Medicine. Diagnosis and treatment of overactive bladder (non-neurogenic) in adults: AUA/SUFU guideline amendment. J Urol. 2015;193:1572-80.

17. Rovner ES, Goudelocke CM. Urodynamics in the evaluation of overactive bladder. Curr Urol Rep. 2010;11:343-7.

18. Selvaraj J, Kekre AN, Varghese L, Jacob KS. Symptoms, prevalence, and risk factors of overactive bladder in women in south India. Int J Gynaecol Obstet. 2015;129:274-5.

19. Neves RCS. Incidência e fatores de risco de bexiga hiperativa em adultos: Resultados de um estudo prospectivo de base populacional. [tese de doutorado]. Salvador: Fundação Osvaldo Cruz. 2010.

20. Fry $\mathrm{CH}$ : Obesity and the Overactive Bladder. Curr Bladder Dysfunct Rep. 2013; 8: 62-68.

21. World Health Organization [homepage on the Internet]. BMI Classification. 2006. Geneva: WHO [cited 2008 nov1 12]. Available at: <http://www.who.int/bmi/index jsp?introPage=intro_3.html>

22. Hirayama A, Torimoto K, Mastusita C, Okamoto N, Morikawa $\mathrm{M}$, Tanaka N, et al. Risk factors for new-onset overactive bladder in older subjects: results of the Fujiwara-kyo study. Urology. 2012;80:71-6.

23. Uzun H, Zorba OÜ. Metabolic syndrome in female patients with overactive bladder. Urology. 2012;79:72-5.

24. Dávila HA, López V, Nieves L, Colantuono A, Guaiquirián L, Sánchez $\mathrm{P}$, et al. Demographic distribution and prevalence of overactive bladder in Venezuela. Actas Urol Esp. 2010;34:176-80.
25. Lapitan MC, Chye PL; Asia-Pacific Continence Advisory Board. The epidemiology of overactive bladder among females in Asia: a questionnaire survey. Int Urogynecol J Pelvic Floor Dysfunct. 2001;12:226-31.

26. Stewart WF, Van Rooyen JB, Cundiff GW, Abrams P, Herzog $A R$, Corey $R$, et al. Prevalence and burden of overactive bladder in the United States. World J Urol. 2003;20:327-36.

27. Milson I, Irwin DE. A cross-sectional, population-based multinational study of prevalence of overactive bladder and lower urinary tract symptoms: Results from the EPIC Study. Eur Urol. 2007; 6:4-9.

28. Herschorn S, Gibbons E. Epidemioilogia na América do Norte. In: Truzzi JC, Dambros M, editors. Bexiga hiperativa: Aspectos práticos. São Paulo: Nome da Rosa; 2009; pp. 25-35.

29. Scafuri A. Epidemiologia na América Latina. In: Truzzi JC, Dambros M, editors. Bexiga hiperativa: Aspectos práticos. São Paulo: Nome da Rosa, 2009; pp. 21-3.

30. Gamburgo LJL, Monteiro MIB. Envelhecimento e linguagem: algumas reflexões sobre aspectos cognitivos na velhice. Rev Kairós. 2007; 10: 35-49.

31. Vallet GT. Embodied cognition of aging. Front Psychol. 2015; 16:6:463.

32. Abrams P, Avery K, Gardener N, Donovan J; ICIQ Advisory Board. The International Consultation on Incontinence Modular Questionnaire: www.iciq.net. J Urol. 2006;175(3 Pt 1):1063-6.

33. Shy M, Fletcher SG. Objective Evaluation of Overactive Bladder: Which Surveys Should I Use? Curr Bladder Dysfunct Rep. 2013;8:45-50.

34. Bomfim IQM, Batista RPS, Lima RMC: Evaluation of sexual function in a group of mastectomized women. Rev Bras Promoç Saúde. 2014; 27: 77-84.

35. Fávero MH, Maurmann EC, Souza CMSG: Desenvolvimento adulto e escolaridade: um estudo sobre a resolução de problemas dedutivos Psicologia em Revista, Belo Horizonte, 2003; 10: 92-107.

36. Ritchie SJ, Bates TC, Deary IJ. Is education associated with improvements in general cognitive ability, or in specific skills? Dev Psychol. 2015;51:573-82.

Correspondence address:

Paulo Roberto Kawano, MD, PhD Departamento de Urologia

Fac. de Medicina da Univ. Est. de São Paulo, UNESP Campus de Rubião Júnior, s/n

Botucatu, SP, 18618-687, Brasil

Telephone: +55 11 3880-1568

E-mail: kawano@fmb.unesp.br 